\title{
LINFADENECTOMIA EM CARCINOMA DE CÉLULAS DE MERKEL AVANÇADO
}

\section{LYMPHADENECTOMY IN ADVANCED MERKEL CELL CARCINOMA}

Lucas Johann Gritsch ${ }^{1}$; Maria Eduarda Turczyn De Lucca ${ }^{1,2}$; Leandro Carvalho Ribeiro ${ }^{2}$ Kátia Sheylla Malta Purim ${ }^{1}$; Letícia Isabel Pedrini²; Sue Hellen Munhos ${ }^{2}$; Anne Karoline Groth²; Rosângela Stadnick Lauth de Almeida ${ }^{1}$.

\section{RESUMO}

Introdução: O Carcinoma de Células de Merkel (CCM), rara neoplasia neuroendócrina de pele, acomete regiões fotoexpostas, com crescimento rápido, caráter agressivo e alta taxa de mortalidade. É diagnosticado por biópsia e imunohistoquímica (IHQ), e o tratamento realizado com cirurgia e terapia adjuvante. Relato do caso: O presente estudo retrata paciente masculino, 74 anos, portador de lesão exuberante em região glútea associada a metástase linfonodal, confirmada por meio de histologia e IHQ de CCM. Submetido a ressecção da lesão, linfadenectomia inguinal aberta e radioterapia (RT). Houve evolução locorregional associada a linfocele, disfunção orgânica múltipla, sepse e desfecho desfavorável. Conclusão: São discutidas a apresentação incomum do caso, sua gravidade, desafios cirúrgicos e complicações.

Palavras-chave: Carcinoma de Células de Merkel. Neoplasia Neuroendócrina. Metástase. Linfocele.

\section{ABSTRACT}

Introduction: Merkel Cell Carcinoma (CCM), a rare neuroendocrine skin neoplasm, affects photoexposed regions, with rapid growth, aggressive behavior, and high mortality rate. It is diagnosed by biopsy and immunohistochemistry as well as its treatment is performed with surgery and adjuvant therapy. Case report: The current study reports a 74-year-old male patient with an exuberant lesion in the gluteal region associated with lymph node metastasis, confirmed through histology and MCC immunohistochemistry. Subjected to resection of the lesion and open inguinal lymphadenectomy and radiation therapy. There was a locoregional progression associated with lymphocele, multiple organ dysfunction, sepsis and unfavorable outcome. Conclusion: The unusual presentation of the case, its severity, surgical challenges, and complications are discussed.

Keywords: Carcinoma. Merkel Cell Carcinoma. Neuroendocrine Neoplasm. Metastasis. Lymphocele.

\section{INTRODUÇÃO}

O CCM é uma neoplasia neuroendócrina incomum, derivada de células da camada basal da epiderme ${ }^{1,2}$. Acomete principalmente homens (2:1) caucasianos entre 70 e 80 anos ${ }^{1,2}$. Sua carcinogênese associa-se à mutação no braço curto do cromossomo 10, que inativaria o gene PTEN (supressor tumoral), e se correlaciona com o Poliomavirus MCPyV, presente em $80 \%$ das células nessa neoplasia1,3. $O$ tumor se implanta preferencialmente em áreas fotoexpostas (cabeça, pescoço e membros) com padrão ulcerativo, e menos frequentemente em não fotoexpostas, como glúteos, exibindo superficie lisa e brilhante ${ }^{4}$.

O diagnóstico é realizado mediante biópsia e IHQ com identificação de fatores tumorais, sendo os principais as citoqueratinas (CK) de baixo peso molecular (CK8, CK18, CK19 e CK20), filamentos intermediários, marcadores neuroendócrinos (CD56, cromogranina ou sinaptofisina), e ausência de expressão de TTF1, MASH1, Citoqueratina 7, proteina S100 e antígeno leucocitário 2,5 .

$\mathrm{O}$ tratamento envolve excisão, radioterapia (RT) e quimioterapia (QT). No entanto, em doença extensa ou metastática, a sobrevida é inferior a $50 \%$ em um ano ${ }^{2,6}$. Quando em região glútea ou inguinal, associa-se linfadenectomia, podendo complicar em $50 \%$ a $90 \%$ dos casos. A principal intercorrência é a linfocele, em que há extravasamento e contenção de linfa nos tecidos adjacentes, processo geralmente autolimitado ${ }^{7}$.

\footnotetext{
${ }^{1}$ Universidade Positivo, Curso de Medicina - Curitiba - PR - Brasil

${ }^{2}$ Hospital Erasto Gaertner - Curitiba - PR - Brasil
} 


\section{RELATO DO CASO}

P.B.M., 74 anos, hipertenso, portador de insuficiência cardiaca e hiperplasia prostática benigna, apresentava lesão dolorosa, edemaciada, ulcerada, móvel, arroxeada em região glútea direita, medindo $15 \times 14 \mathrm{~cm}$. A tomografia computadorizada (TC) demonstrou lesão de grandes dimensões, edema, distorções anatômicas e metástases para linfonodos inguinais, medindo $4 x 5 \mathrm{~cm}$ (Figura 1).

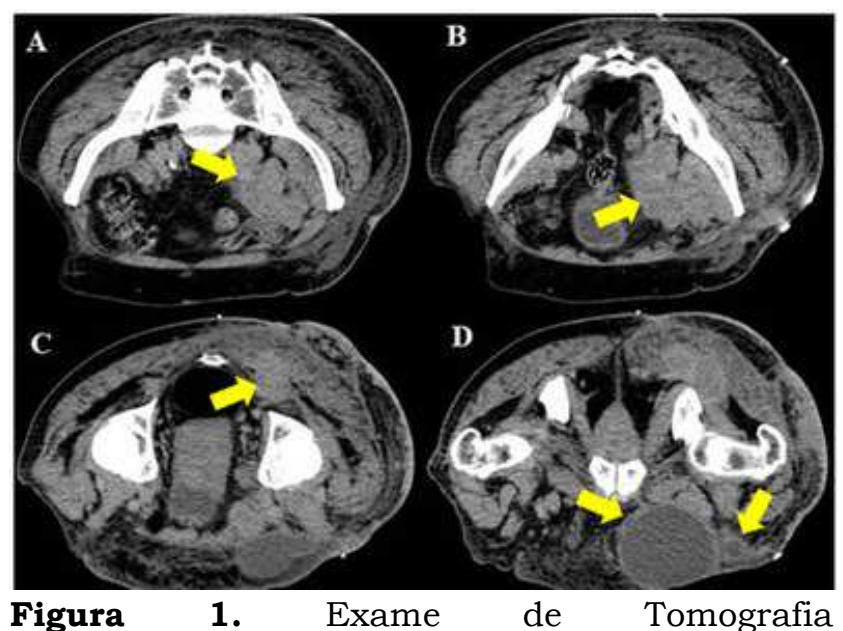

Computadorizada de pelve. A e B. As setas indicam lesão em pelve sem plano de clivagem com iliopsoas direito e envolvimento circunferencial dos vasos ilíacos. C. Lesão glútea à direita se estendendo até o osso ilíaco. D. Lesões císticas inguinais à direita, provavelmente correspondendo a linfonodomegalias necróticas.

Foi realizada ressecção da lesão em nádega direita e na profundidade da emergência do nervo ciático, seguida de linfadenectomia iliaco-inguinal e retalho fasciocutâneo em região posterior da coxa. $\mathrm{O}$ anatomopatológico (AP) demonstrou CCM pouco diferenciado, com margens radiais livres e metástase inguinal à direita. As medidas após remoção foram $12 \times 11 \mathrm{~cm}$ e $6 \mathrm{~cm}$ de espessura. O índice mitótico foi de 18 mitoses $/ \mathrm{mm}^{2}$, com infiltrado linfocitário peri e intratumoral discreto e invasão angiolinfática. A IHQ foi positiva para CK AE1/AE3, CK 20, cromogranina, sinaptofisina e KI 67 (em 40\% dos núcleos das células neoplásicas) e negativa para proteína S-100 (Figura 2). O paciente foi encaminhado para RT adjuvante, não instaurada por aumento de volume em região inguinal direita, dor e linfedema escrotal, compativel com linfocele, o submetendo a drenagem em 3 ocasiões.

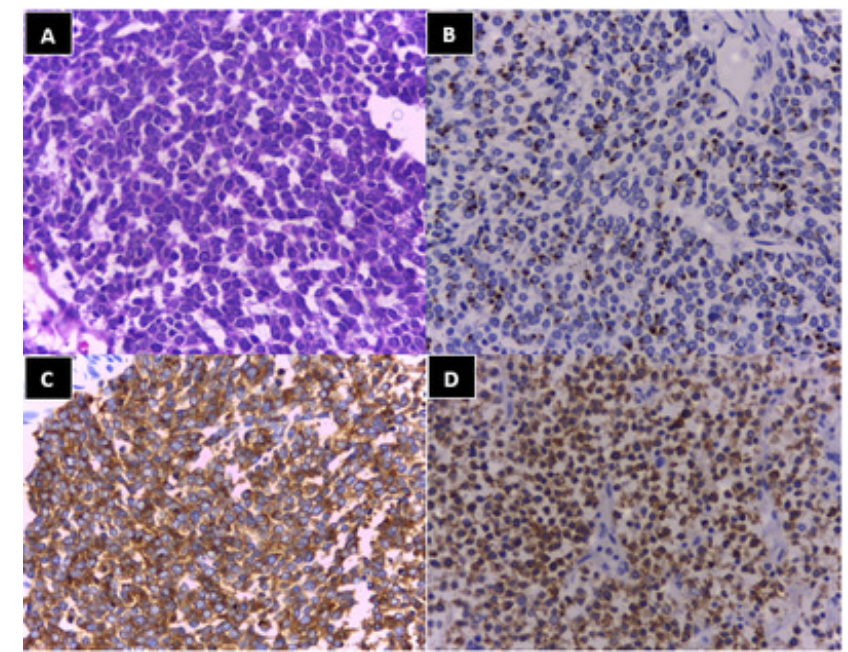

Figura 2. Carcinoma de Células de Merkel.

A. Neoplasia de células pequenas redondas e azuis com citoplasma escasso. B. Expressão clássica de CK20 com padrão paranuclear.

C. Expressão citoplasmática difusa de sinpatofisina. D. Expressão citoplasmática difusa de cromogranina (colorações em hematoxilina e eosina ou imunoperoxidase, magnificação original x400).

Três meses após a cirurgia, identificou-se evolução extensa em região glútea e pelve, caracterizando a lesão como irressecável. Foi indicada QT com cisplatina e etoposídeo, não instituída devido a deterioração clínica, seguida de óbito por quadro séptico.

\section{DISCUSSÃo}

O CCM é raro, agressivo (mortalidade de $65 \%$ ) e de rápida expansão $2,3,8$. Em geral, mede 2 a $4 \mathrm{~cm}$, contrapondo as lesões do caso. O tamanho e profundidade não representam a gravidade ou predizem metástases, no entanto, a localização (tronco e extremidades) e disseminação reduzem a sobrevida6,9. No caso, devido a disseminação linfonodal ao diagnóstico, presume-se identificação tardia do $\mathrm{CCM}^{8}$.

Classicamente, há nódulo único, assintomático, delimitado, móvel, eritematovioláceo, associado a telangiectasias e padrão ulcerativo ou superficie lisa e brilhante. No relato, contudo, apresenta-se arroxeado, ulcerado e móvel, a despeito da localização em área não fotoexposta 4 .

O AP apresentou lesões pouco diferenciadas, margens radiais livres e metástase em linfonodos inguinais à direita. Ainda, a IHQ foi compativel com CCM, devido a identificação de CK e outros marcadores específicos, bem como a 
ausência de expressão da proteína S-1002,8. Diante da importância do acometimento linfonodal, precedendo a biópsia do linfonodo sentinela, recomenda-se realizar uma ultrassonografia regional, TC ou TC por emissão de pósitrons ${ }^{9}$.

Acerca do tratamento, realiza-se excisão cirúrgica e terapia adjuvante ${ }^{10}$. Em geral, com margens de 1 a $3 \mathrm{~cm}$ e, quando disponível, é feito controle microscópico. Nos tumores com linfonodos clinicamente negativos, recomenda-se biópsia do linfonodo sentinela e, se micrometástases, indica-se linfadenectomia terapêutica. Naqueles com acometimento identificado, após a ressecção, pode ser necessária RT. Em lesões de membros inferiores com metástases para linfonodos inguinais, a ressecção envolve a cadeia inguinal, ilíaca e obturatória. A morbidade do procedimento varia de $17 \%$ a $90 \%{ }^{3}$. Foi demonstrado aumento do intervalo e diminuição da recorrência locorregional ao realizar linfadenectomia eletiva ${ }^{11}$.

A RT foi indicada em razão do índice mitótico de 18 mitoses $/ \mathrm{mm}^{2}$ e incursão ganglionar, visto ser preconizada quando há invasão ganglionar, margens cirúrgicas escassas, mais de 10 mitoses $/ \mathrm{mm}^{2}$ ou tumores irressecáveis. A RT está associada à diminuição da recorrência locorregional e aumento da sobrevida1,9.

A QT pode ser indicada nos casos com metástases à distância. O tumor costuma ser sensivel à cisplatina, doxorrubicina e fluorouracil1,6,8. No caso, apesar de indicada, devido ao falecimento do paciente, não foi instituída a QT. Após o tratamento, há recorrência local em 20\% $75 \%$ dos casos, metástases regionais e à distância em $31 \%$ - $80 \%$ e 26\% - 75\%, respectivamente 6 . A sobrevida é de $50 \%$ ou menos em 5 anos, a despeito do tratamento, se houver acometimento linfonodal. O status linfonodal é o principal preditor da sobrevida ${ }^{9,11}$.

Posteriormente à ressecção, o paciente evoluiu com linfocele volumosa em região inguinal direita, necessitando de aspiração e drenagem em múltiplas ocasiões. Essa é a complicação mais comum após linfadenectomia (12\% a 40\% dos casos), seguida de seromas (23\%) e linfedema $(33 \%)^{7}$. O manejo conservador da linfocele consiste em aspirações repetitivas e compressão, no entanto, há elevada recorrência, podendo ser adotado um sistema de drenagem percutânea. Outras opções são a escleroterapia ou ligadura macroscópica dos vasos lesados e a microcirurgia. As duas primeiras aumentam o risco de linfedema. Por fim, o tratamento ideal para linfocele recorrente pós-linfadenectomia não é bem estabelecido ${ }^{12}$.

No caso, optou-se por linfadenectomia iliaca videolaparoscópica e inguinal aberta à direita. Esse é o padrão ouro para ressecção dos linfonodos com metástase, apesar da elevada morbidade ${ }^{13}$. A fim de reduzir complicações, foi realizada incisão inguinal superior, 3 a $4 \mathrm{~cm}$ acima do ligamento inguinal. Essa é uma opção viável, segura, econômica e mais precisa na dissecção da fáscia de Camper. As complicações envolvidas na linfadenectomia podem prolongar o pós-operatório e dificultar ou interromper o tratamento adjuvante $^{13}$.

O tratamento do CCM envolve ressecção da lesão, linfadenectomia, RT e QT, no entanto, a sobrevida em 5 anos é de $0 \%$ a $18 \%$ nos casos avançados ${ }^{11,14}$. A via videolaparoscópica e a dissecção linfonodal robótica (DLR), apresentam morbidade inferior a cirurgia aberta 7 . Contudo, mais estudos ainda são imprescindiveis ${ }^{13}$.

\section{REFERÊNCIAS}

1. Campillo R, Gil-Carcedo E, Alonso D, Vallejo LA, Juan MO. Carcinoma neuroendocrino primario de la piel, carcinoma de células de Merkel. Casuística 1991-2012. Acta Otorrinolaringológica Española. 2013;64(6):396-402.

doi: 10.1016/j.otorri.2013.06.003.

2. Llombart B, Requena C, Cruz J. Actualización en el carcinoma de células de Merkel: Epidemiología, etiopatogenia, clínica, diagnóstico. Actas Dermo-Sifiliogriaficas. 2017;108(2):108-19. doi: $10.1016 /$ j.ad.2016.07.022.

3. Gonçalves $M$, Varella $R$, Almeida $N$, Guimarães M, Luz F. Molecular detection of Merkel cell polyomavirus in basal cell carcinoma and perilesional tissue: a cross-sectional study. An. Bras. Dermatol. 2020;95(4):527-8. doi: 10.1016/j.abd.2019.10.007.

4. Marcoval J, Ferreres JR. Características clínicas del carcinoma 
de células de Merkel. Actas DermoSifiliogriaficas. 2017;108(9):887. doi: $10.1016 /$ j.ad.2017.04.020.

5. Dañino-García M, Domínguez-Cruz JJ, Pérez-Ruiz C, Conejo-Mir J, PereyraRodriguez JJ. Características clínico-epidemiológicas del carcinoma de células de Merkel en una serie de 38 pacientes. Actas DermoSifiliogriaficas. $\quad 2019 ; 110(5): 360-5$. doi: 10.1016/j.ad.2018.09.007.

6. Caselli G, Ocares M, Benavides C, Delgado C, Caselli B, García C, et al. Carcinoma de células de merkel en la región perianal: reporte de un caso. Rev Chil Cir. 2009;61(4):378-80. doi: 10.4067/S0718-40262009000400014

7. Gkegkes I, Minis E, Iavazzo C. Robotic-assisted inguinal lymphadenectomy: a systematic review. J Robot Surg. 2019;13(1):1-8.

doi: $10.1007 / \mathrm{s} 11701-018-0823-4$.

8. Almeida MWR, Lopes CC, Almeida Júnior HL, Costa LE. Carcinoma de células de Merkel em extremidade inferior. Rev. Col. Bras. Cir. 2012;39(2):165-7.

9. Lebbe C, Becker J, Grob J, Malvehy J, del Marmol V, Pehamberger $\mathrm{H}$, et al. Diagnosis and treatment of Merkel Cell Carcinoma. European consensusbased interdisciplinary guideline. Eur J Cancer. 2015;51(16):2396-403. doi: 10.1016/j.ejca.2015.06.131.

10. Saavedra JA, Batich K, Montero FC, et al. Merkel cell carcinoma demographics, morphology, and survival based on 3870 cases: a population based study. J Cutan Pathol. 2010;37(1):20-7. doi: 10.1111/j.16000560.2009.01370.x.

11. Messina J, Reintgen D, Cruse C, Rappaport D, Berman C, Fenske N, et al. Selective lymphadenectomy in patients with Merkel cell (cutaneous neuroendocrine) carcinoma. Ann Surg Oncol. 1997;4(5):389-95.

doi: $10.1007 /$ BF02305551.

12. Giacalone G, Yamamoto T, Hayashi A, Belva F, Gysen M, Hayashi N, et al. Lymphatic supermicrosurgery for the treatment of recurrent lymphocele and severe lymphorrhea. Microsurgery. 2019;39(4):326-31. doi: $10.1002 /$ micr.30435.
13. Manci N, Marchetti C, Esposito F, De Falco C, Bellati F, Giorgini M, et al. Inguinofemoral Lymphadenectomy: Randomized Trial Comparing Inguinal Skin Access Above or Below the Inguinal Ligament. Ann Surg Oncol. 2009;16(3):721-8. doi: $10.1245 / \mathrm{s} 10434-008-0216-4$.

14. Schadendorf D, Lebbé C, zur Hausen A, Avril M, Hariharan S, Bharmal M, et al. Merkel cell carcinoma: Epidemiology, prognosis, therapy and unmet medical needs. Eur J Cancer. 2017;71:53-69.

doi: 10.1016/j.ejca.2016.10.022.

Fonte de financiamento: Não

Conflito de interesses: Não

Data de Submissão: 10 Janeiro 2021

Decisão final: 30 Agosto 2021

\section{Autor de Correspondência:}

Maria Eduarda Turczyn De Lucca

E-mail: mariatdelucca@gmail.com lucasgritsch@hotmail.com 